\title{
Relationship Between Dysfunctional Eating Attitudes and Parental Marital Status in Female Adolescents
}

\author{
Neslim Guvendeger Doksat ${ }^{1}$, , Gamze Korkmaz ${ }^{2}$ \\ ${ }^{1}$ Department of Psychology, Faculty of Arts and Sciences, Beykent University, Istanbul, Turkey \\ ${ }^{2}$ Department of Counselling and Psychological Services, Doğa Anadolu High School, Bayrampaşa, Istanbul, Turkey
}

Email address:

neslimdoksat@doksat.com (N. G. Doksat), gamze19901@gmail.com (G. Korkmaz)

${ }^{*}$ Corresponding author

\section{To cite this article:}

Neslim Guvendeger Doksat, Gamze Korkmaz. Relationship Between Dysfunctional Eating Attitudes and Parental Marital Status in Female Adolescents. Psychology and Behavioral Sciences. Vol. 8, No. 1, 2019, pp. 26-32. doi: 10.11648/j.pbs.20190801.14

Received: December 19, 2018; Accepted: February 20, 2019; Published: March 6, 2019

\begin{abstract}
The purpose of this study is to investigate the relationship between dysfunctional eating attitudes and anorexic or bulimic symptoms with regard to the marital status of parents and also to investigate the difference in eating attitudes scores by means of body and weight satisfaction in adolescents. 60 adolescent girls attending high school participated in the study. Half of the involved participants consisted of families whose parents lived together, and the other half had divorced parents. The questionnaire data collection method was used in this study. A moderately severe significantly positive relationship was found between eating attitudes and both anorexic and bulimic symptoms scales in participants whose parents lived separately or got divorced. The group of participants whose parents were divorced and who presented higher scores in anorexic symptoms also scored statistically significantly higher on the parameter of eating attitudes median. The participants who were dissatisfied with their weight scored the highest eating attitudes scales median when compared to the participants who had body dissatisfaction. Selective prevention and treatment methods should be used during adolescence to prevent eating disorders. Special attention should be paid to body image disturbances, inappropriate weight control behaviors, and disturbed self-perceived weight during adolescence in order to prevent eating disorders.
\end{abstract}

Keywords: Eating Attitudes, Family Features, Adolescent Girls

\section{Introduction}

"Eating disorders (EDs) are characterized by restricted or chaotic food intake, a morbid preoccupation with food, weight, and shape and a distorted body image. The Diagnostic and Statistical Manual of Mental Disorders (DSM-5) defines eating disorders as anorexia nervosa, bulimia nervosa, binge eating disorder, other specified feeding and eating disorders, and unspecified feeding and eating disorders" [1]. Eating disorders may lead to various psychiatric and physical problems in youth. "Persistent unhealthy eating habits may cause eating disorders (ED), which are a serious group of mental illnesses characterized by abnormal eating habits" [2].

Adolescence is an essential period, which is related to major physical, social, and cognitive developmental changes, involving significant concerns about the body size [3], and during which the concept of weight status often has a negative impact on mental health in adolescents [4]. Studies evaluating the incidence of misinterpretation of weight perception against the actual weight status reported this condition to be more obvious in females using various weight control behaviors which were mostly motivated by perceived weight, rather than the actual body mass index. This kind of motivation causes dysfunctional eating attitudes such as overeating, binge eating or starvation habits [5].

Studies investigating the effects of interfamily relationships on dysfunctional eating attitudes in adolescents have established several perspectives. A published article [6] on studies covering family features suggested that "lower family cohesion, connectedness, and adaptability were predictive of binge eating and the use of extreme weight loss behaviors, such as vomiting and crash dieting among adolescent females." Coherently, little evidence of an association between marital status change or maternal 
satisfaction scores with problematic eating attitudes has been reported in the offspring [7]. As a supporting idea, the efficacy of family therapies has been suggested in cases of children whose eating attitudes have been affected by marital conflicts [8]. It has recently been suggested that parental divorce created a potential risk factor for the development of eating pathology [9]. The goal of this study was to investigate the relationship between dysfunctional eating attitudes and anorexic or bulimic symptoms with regard to the marital status of parents. Identifying the risk groups for eating disorders with regard to interfamily relations is an important issue in maintaining mental health and planning preventive strategies against dysfunctional eating attitudes in adolescents.

\section{Theoretical Background}

\subsection{Prevalence and Prognosis of Eating Disorders in Adolescence}

According to the studies, "adolescent eating disorders, including anorexia nervosa, bulimia nervosa, and binge eating disorder, affect $0.3-1.6 \%$ of boys and girls aged $13-18$ years in the USA, with additional $2.5-10 \%$ being affected by subthreshold eating conditions." [10]. It was reported that the early detection and treatment of EDs may end up with full recovery [11]. Consistently, it was suggested that screening for EDs in high school students using practical and valid scales may give a chance for early detection and appropriate early intervention [12].

\subsection{Perceived Weight and Body Image}

Perceived overweight adolescents presented a higher possibility of anxiety and depression symptoms when compared to perceived normal and underweight adolescents [13]. Female college students were reported to be keener on looking forward to being thin compared to males, both in Western and Asian samples [14]. Another study conducted on Turkish adolescent females attending high school reported that the psychological well-being of adolescents is more associated with body satisfaction in comparison with the actual and perceived weight status [15].

It was shown that increased psychological problems and low self-esteem could lead to problems such as dissatisfaction with body image and abnormal eating behavior. Therefore, adolescents tend to overthink about their appearances, and they may change their eating attitudes [16]. A published study described one of these predicting factors as the concept of "internalization of the thin ideal," meaning "the degree to which an individual has accepted social values of thinness and applies these values to herself" [17]. There are both contradicting studies that underscore the importance of this concept and related weight concerns as contributing psychosocial risk factors for eating disorders [18] and supporting reports which suggest that "thin-ideal internalization predicts disordered eating attitudes indirectly through body dissatisfaction and also directly through disordered eating attitudes" [19-21].

The concept of body image included dissatisfaction with the size or shape of the body or misperceptions of the body image, such as describing that one's body is larger or smaller in comparison with the perceived ideal [22]. Furthermore, the "distorted body image" concept was regarded as "perception of the self as heavy or thin while presenting with a normal weight." Results of the involving study suggested that a distorted body image during preadolescence is associated with being overweight or underweight in the following years [23]. It was reported that disordered eating was positively associated with the internalization of the thin ideal, weight-related anxiety and negatively associated with body image satisfaction. Therefore, these factors were determined to be significant predictors of disordered eating attitudes [24]. This idea was supported by [17], which suggested that weight, disordered eating and body image dissatisfaction scores increased in the first years of college and that they were predicted by the early implicit internalization of the thin ideal. It was shown that the disordered eating behavior showed changes more by weight perception than by weight status in Kuwaiti college women [25]. The parallel results of another study carried out [26] showed that adolescents' self-perception of being overweighed was associated with unhealthy weight control behaviors during the young adulthood period. Another supporting study on this issue [27] suggested that significantly greater overvaluation of shape, weight and significantly reduced weight satisfaction distinguished women with binge eating disorder (BED) from those without BED. On the contrary, another study has suggested that body dissatisfaction increases the risk of bulimic pathology in the following years [28].

\subsection{Interfamily Relations and Dysfunctional Eating Attitudes}

It was suggested that "soft and warm relations in the family affect adolescents" cognitions" and that "family connectedness and a positive family mealtime environment have been found to be inversely associated with unhealthy weight control behaviors, and body dissatisfaction" among adolescents [29]. Similarly, another study [30] proposed that "overweight in adolescence is associated with greater family conflict and less family cohesion." Another conducted supporting study [31] reported that greater family functioning impairment is associated with more severe eating disorder psychopathology. Similarly, another study demonstrated that children exposed to maladaptive parental behavior exhibit more tendencies to developing eating disorders [32]. Considering the four last studies listed above, another study [33] suggested that, although previous studies on eating disorders regarded family dysfunction as directly associated with the development of eating psychopathology, "not all of the following publications identified a specific family structure or a dysfunctional pattern typical for eating disorders." On the contrary, another study reported that parental warmth is associated with a positive outcome in 
anorexic patients [34]. Another conducted supporting study [26] reported that: "Adolescent family factors were significantly associated with unhealthy weight control behaviors in underweight/normal weight females." Similarly, it was suggested that women who perceive "higher levels of social safeness tend to present a more positive and respectful attitude towards their body and decreased attitudes of disordered eating behavior" [35]. Although etiological factors related to this issue are controversial, a study [36] presented that "significantly higher heritability of body dissatisfaction in twins from divorced versus intact families and that parental divorce may act as an environmental "trigger" that enhances genetic predispositions for disordered eating through gene-environment interactions (GxE) which are specific only for body dissatisfaction." Another study carried out on this issue [37] suggested that: "Specifically, parental divorce may act as a trigger of genetic predispositions for the negative self-evaluation component of body dissatisfaction, but not the perceived deviation of current body shape from ideal."

It was concluded that adolescents with anorexia nervosa report greater family impairment [34]. Another recent focus on interfamily relationships was emphasized by a number of studies. For example, it was reported that family-based treatment (FBT) was developed with the understanding that families may restructure dysfunctional eating attitudes of children in time, in response to $\mathrm{AN}$ [33]. It was also concluded that "the aim of FBT is letting parents take control over food and eating, which is a preoccupation for the patient with anorexia nervosa" and that "FBT could significantly reduce hospital readmission days and improve remission rates in anorexic adolescents" [38]. Similarly, the effectiveness of parent-focused treatment in adolescents with anorexia nervosa suggested the importance of the parent-child relationship in anorexic patients [39]. All of these investigational results highlight the importance of interfamily relations for dysfunctional eating attitudes in adolescents.

\subsection{The Current Study}

The present study was conducted to investigate the relationship between dysfunctional eating attitudes and anorexic or bulimic symptoms with regard to the marital status of parents and also to investigate the difference in eating attitude scores by means of body and weight satisfaction in adolescents.

\section{Material and Methods}

\subsection{Sampling of the Participants}

The sample of the study consisted of 60 female students with the mean age of $15.65 \pm 1.30$ years, studying in private schools located in Avc1lar, Bahcelievler, Basaksehir, Halkal1, Beykent, Bahcesehir, and Florya districts of Istanbul province in the 2016-2017 academic years. 30 of the involved participants consisted of families whose parents lived together, whereas the other 30 participants had divorced parents. Participation was ensured on a voluntary basis, and the students were included in the study via simple random sampling. The study was conducted in accordance with the Helsinki Ethics Declaration. The compliance of the paper with ethical rules is under the responsibility of the authors. The authors worked in accordance with the principles of this declaration, and they conducted the study after receiving the "informed volunteering consent form" from the participants within the scope of the study.

\subsection{Instruments}

\subsubsection{Personal Information Form}

It is a form which includes demographic information such as age, economic situation, and family structure of the participants determined by the researcher.

\subsubsection{Eating Attitudes Test-40 (EAT-40)}

This test was developed to measure the attitudes of individuals with eating disorders. The scale consists of forty 6-point Likert-type questions [40]. The reliability and validity studies of the scale in Turkish were conducted in 1989, and the researchers reported that this test was useful in measuring the symptoms of anorexia nervosa objectively. The increase in the score obtained from the scale is interpreted as an eating disorder [41].

\subsubsection{Bulimic Investigatory Test, Edinburgh (BITE)}

This is a 33-item test (with a total of 36 questions, including an item with four questions) which includes questions about eating habits, eating, attitudes, and weight in bulimia. The first 30 items answered as "Yes" or "No" are associated with the symptoms, and those answered as "Yes" receive one point. The first five items are scored reversely. There are 6 questions related to the severity of the symptoms, and these questions have five to seven options. Obtaining a score of 20 or more from the test indicates the presence of binge eating. The values between 10 and 19 indicate the abnormal eating pattern and the values below 10 indicate the absence of binge eating. The Cronbach's alpha reliability coefficient is .87 for the symptom subscale and .62 for the severity subscale [42]. The validity and reliability studies of the scale in Turkish were conducted with university students [43].

\subsection{Procedure and Data Analysis}

The participants were asked to fill in the questionnaire form including the scales and forms on a voluntary basis. It took an average of 10 minutes to fill in a questionnaire, and the collected data were classified and analyzed. Nonparametric tests were preferred because the sample number was low and the data did not show normal distribution. Spearman's correlation analysis, the MannWhitney $\mathrm{U}$ test, and the Kruskal-Wallis $\mathrm{H}$ test were used to analyze the data. The results were interpreted at the significance level of $\mathrm{p}=0.05$ and $\mathrm{p}=0.01$. 


\section{Results}

\subsection{Demographic Information of the Participants}

Sixty girls participated in the study. Thirty of the involved participants consisted of families whose parents lived together, whereas the other thirty participants had divorced parents. In the group of participants whose parents lived together, it was observed that the economic status was generally good $(53.3 \%)$, the nuclear families constituted the majority $(96.4 \%), 43.3 \%$ of the participants were satisfied with their bodies and $37.9 \%$ of them were not satisfied with their weight (as shown in Table 1). In the group of participants whose parents were divorced, it was observed that the economic status was generally good $(50.0 \%)$, the fragmented families constituted the majority (56.7\%), 40.0\% of the participants reported a good status of body satisfaction, $40.0 \%$ of them were unsure about their body satisfaction status, $36.7 \%$ of them reported a low weight satisfaction status, and $40.0 \%$ of them were unsure about their weight satisfaction status (as shown in Table 1).

Table 1. Number and Percentage Distribution of the Participants' Demographic Information.

\begin{tabular}{|c|c|c|c|c|c|}
\hline \multirow{2}{*}{ Variables } & & \multicolumn{2}{|c|}{ Parents living together } & \multicolumn{2}{|c|}{ Divorced parents } \\
\hline & & $\mathbf{n}$ & $\%$ & $\mathbf{n}$ & $\%$ \\
\hline \multirow{4}{*}{ Family's economic status } & Low & 3 & 10.0 & 1 & 3.3 \\
\hline & Medium & 9 & 30.0 & 12 & 40.0 \\
\hline & Good & 16 & 53.3 & 15 & 50.0 \\
\hline & Very good & 2 & 6.7 & 2 & 6.7 \\
\hline \multirow[b]{2}{*}{ Family structure } & Nuclear & 27 & 96.4 & 12 & 40.0 \\
\hline & Extended & 1 & 3.6 & 1 & 3.3 \\
\hline \multirow{3}{*}{ Body satisfaction status } & Yes & 13 & 43.3 & 12 & 40.0 \\
\hline & No & 9 & 30.0 & 6 & 20.0 \\
\hline & I am not sure & 8 & 26.7 & 12 & 40.0 \\
\hline \multirow{3}{*}{ Weight satisfaction status } & Yes & 8 & 27.6 & 7 & 23.3 \\
\hline & No & 11 & 37.9 & 11 & 36.7 \\
\hline & I am not sure & 10 & 34.5 & 12 & 40.0 \\
\hline Total & & 30 & 100.0 & 30 & 100.0 \\
\hline
\end{tabular}

\subsection{Relationship Between Eating Attitude Scores, Anorexic and Bulimic Symptoms According to the Parental Marital Status}

The relationship between eating attitude scores, anorexic and bulimic symptoms according to the parental marital status was examined by Spearman's correlation analysis. It was observed that there was no significant relationship between eating attitude scores and bulimic symptoms $(\mathrm{r}=0.103 ; \mathrm{p}>0.05)$ and anorexic symptoms $(\mathrm{r}=0.297 ; \mathrm{p}>0.05)$ for the participants whose parents lived together. On the other hand, it was observed that there was a significant positive and moderate correlation between eating attitude scores and bulimic symptoms $(\mathrm{r}=0.533 ; \mathrm{p}<0.01)$ and anorexic symptoms $(\mathrm{r}=0.489 ; \mathrm{p}<0.01)$ for the participants whose parents were divorced. According to the findings, it was concluded that anorexic and bulimic symptoms increased as the eating attitude scores worsened in those whose parents were divorced (as shown in Table 2).

Table 2. Examination of the Relationship Between Eating Attitude Scores, Anorexic and Bulimic Symptoms According to the Parental Marital Status.

\begin{tabular}{|c|c|c|c|c|}
\hline & & & Bulimic symptoms & Anorexic symptoms \\
\hline \multirow{2}{*}{ Parents living together (30) } & \multirow{2}{*}{ Eating attitude score } & $\mathrm{R}$ & 0.106 & 0.297 \\
\hline & & $\mathrm{P}$ & 0.578 & 0.111 \\
\hline \multirow{2}{*}{ Divorced parents (30) } & \multirow{2}{*}{ Eating attitude score } & $\mathrm{R}$ & $0.533^{* *}$ & $0.489^{* *}$ \\
\hline & & $\mathrm{P}$ & 0.002 & 0.006 \\
\hline
\end{tabular}

${ }^{* *} \mathrm{p}<0.01$

\subsection{Difference Between Eating Attitude Scores of Participants According to the Parental Marital Status, Anorexic and Bulimic Symptoms}

According to the Mann-Whitney $U$ test, there was a significant difference between the participants' eating attitude score medians in terms of the parental marital status $(\mathrm{z}=-$ $2.183 ; \mathrm{p}<0.05)$ and anorexic symptoms. It was observed that the eating attitude medians of the participants, whose parents were divorced and who had high anorexic symptoms, were significantly higher (as shown in Table 3).

Table 3. Examination of the Difference Between the Eating Attitude Scores of Participants According to the Parental Marital Status, Anorexic and Bulimic Symptoms.

\begin{tabular}{lllll}
\hline Categories & N & Mr & tr & Z \\
\hline Parents living together & 30 & 25.58 & 767.50 & \\
Divorced parents & 30 & 35.42 & 1062.50 & -2.183 \\
High anorexic symptoms & 14 & 42.29 & 592.00 & $0.029^{*}$ \\
\hline
\end{tabular}




\begin{tabular}{llllll}
\hline Categories & N & Mr & tr & Z & P \\
\hline Low anorexic symptoms & 46 & 26.91 & 1238.00 & & \\
High bulimic symptoms & 29 & 33.41 & 969.00 & 1.251 & 0.211 \\
Low bulimic symptoms & 31 & 27.77 & 861.00 & & \\
\hline
\end{tabular}

$\mathrm{mr}=$ mean rank; tr $=$ total rank; ${ }^{*} \mathrm{p}<0.05 ;{ }^{* *} \mathrm{p}<0.01$

\subsection{Difference Between Eating Attitude Scores of the Participants According to the Body and Weight Satisfaction Status}

As a result of the Kruskal-Wallis $H$ test conducted, while there was a significant difference between the participants' eating attitude medians according to the weight satisfaction categories $\left(\chi_{(2)}^{2}=8.982 ; \mathrm{p}<0.05\right)$, there was no significant difference for body satisfaction. The participants who were not satisfied with their weight had the highest eating attitude scale median (as shown in Table 4).

Table 4. Examination of the Difference Between Eating Attitude Scores of Participants According to the Body and Weight Satisfaction Status.

\begin{tabular}{|c|c|c|c|c|c|}
\hline Variable & Categories & $\mathbf{N}$ & $\mathbf{m r}$ & $\chi^{2}$ & $\mathbf{P}$ \\
\hline \multirow{3}{*}{ Body satisfaction status } & Yes & 25 & 28.46 & \multirow{3}{*}{3.333} & \multirow{3}{*}{0.189} \\
\hline & No & 15 & 37.60 & & \\
\hline & I am not sure & 20 & 27.73 & & \\
\hline \multirow{3}{*}{ Weight Satisfaction status } & Yes & 15 & 20.20 & \multirow{3}{*}{8.982} & \multirow{3}{*}{$0.011^{*}$} \\
\hline & No & 22 & 37.36 & & \\
\hline & I am not sure & 22 & 29.32 & & \\
\hline
\end{tabular}

${ }^{*} \mathrm{p}<0.05$

\section{Discussion}

In this study, there was no statistically significant relationship between eating attitudes and neither anorexic nor bulimic symptoms scales in participants who lived with their parents. At the same time, a moderately severe significantly positive relationship was found between eating attitudes and both anorexic and bulimic symptoms scales in participants whose parents lived separately or got divorced. These results are compatible with the findings of the studies [9, 26], which were mentioned above. As the eating attitude scale scores worsened, anorexic and bulimic symptoms scale scores also increased. Moreover, these results support the results of the other studies [7, 29, 32], which were mentioned before.

The results of this study also revealed that the group of the participants whose parents were divorced and who presented higher scores in anorexic symptoms also scored statistically significantly higher on the parameter of the eating attitude median. These results are compatible with the previously published reports [33-34, 39] and the report [38], which pointed out the importance of family-based treatment (FBT) that may restructure the dysfunctional ways of eating attitudes and shorten the hospitalization period in patients with anorexia nervosa.

The results of this study showed that the participants who were dissatisfied with their weight scored the highest eating attitude scale median, whereas the same result was not obtained in the participants who were dissatisfied with their body image. This finding is consistent with the results of the studies [25, 27]. Similarly, our results are compatible with the results of the studies [23, 26] published previously. Our findings are also consistent with the study [24], which reported that weight-related anxiety is predictive for unhealthy eating attitudes. On the contrary, this study contradicts with the results of [19-21], who reported that body dissatisfaction is a risk factor for eating pathology.

The data of this study are limited to the private schools in Istanbul where the study was conducted and a total of 60 students receiving education in the 2016-2017 academic years. The demographic variables used in the study are limited to the information given by the students and their responses to the scales. The data obtained from the measurement tools used in the study do not indicate causeeffect relationships. They only explain the relationship between the variables.

\section{Conclusion}

This study was conducted to investigate the relationship between dysfunctional eating attitudes with regard to the marital status of parents. The results of this study showed a positive relationship between eating attitudes and anorexic and bulimic symptoms scales in adolescents whose parents lived separately or got divorced. Additionally, it was found out that the participants, who were dissatisfied with their weight, scored the highest eating attitude scale median. Eating disorders represent a serious group of illnesses both through their direct psychological effects and also through anxiety and depression comorbidities indirectly. Therefore, great attention should be paid to body image disturbances during adolescence to prevent eating disorders.

As a summary, the results of this study support the previous knowledge that increased psychological problems and low self-esteem could lead to problems such as dissatisfaction with the body image and abnormal eating behavior and may contribute to identifying the risk groups for eating disorders with regard to interfamily relationships. Thus, this study may provide guidance in planning preventive strategies against dysfunctional eating attitudes in adolescents. Peer-related interventions addressing the challenges about internalization of the thin ideal may help to 
protect against the development of eating pathology. Selective prevention methods such as screening and educational programs regarding appropriate weight control behaviors and self-perceived weight, targeting young females who have dysfunctional eating habits, can be used for the psychological well-being of adolescents in social samplings such as high schools, for early detection and appropriate early intervention in maintaining mental health.

\section{Acknowledgements}

We would like to thank all participants in the Avcrlar, Bahcelievler, Basaksehir, Halkalı, Beykent, Bahcesehir, and Florya districts of Istanbul province for participating in the research.

\section{Funding}

This research was not supported by any funding.

\section{Conflicts of Interests}

We have no conflicts of interest.

\section{References}

[1] American Psychiatric Association. (APA) (2013). The Diagnostic and Statistical Manual of Mental Disorders: DSM5, fifth ed. American Psychiatric Association, Washington DC.

[2] Erskine, H. E., Whiteford, H. A., Pike, K. M. (2016). The global burden of eating disorders. Curr Opin Psychiatry, 29 (6), 346-353.

[3] Lawler, M., Nixon, E. (2011). Body dissatisfaction among adolescent boys and girls: The effects of body mass, peer appearance culture and internalization of appearance ideals. Journal of Youth and Adolescence, 40, 59-71.

[4] Wang, F., Wild, T., Kipp, W., Kuhle, S., Veugelers, P. (2009). The influence of childhood obesity on the development of self-esteem. Health Reports, 20, 21-27.

[5] Cheung, P. C., Ip, P. L., Lam, S. T., Bibby, H. (2007). A study on body weight perception and weight control behaviours among adolescents in Hong Kong. Hong Kong Med J, 13 (1), 16.

[6] Wertheim, E., Paxton, S., Maude, D., Szmukler, G. I., Gibbons, K., Hillier, L. (1992). Psychosocial predictors of weight loss behaviors and binge eating in adolescent girls and boys. Int J Eat Disord, 12, 151-160.

[7] Wade, K. H., Skugarevsky, O., Kramer, M. S., Patel, P. R., Bogdanovich, N., Vilchuck, K., Sergeichick N., Richmond R., Palmer T., Smith, G. D., Gillman, M. Oken, E., Martinpective, R. M. (2014). Associations of parental smoking, alcohol use, marital status, maternal satisfaction, and parental and childhood body mass index at 6.5 years with later problematic eating attitudes. Nutrition \& Diabetes, 4 (1) e100.

[8] F. Bal, "Psikolojik açıdan normal ve otistik çocuklarda beslenme bozukluğu" in Sosyal ve Beşeri Bilimlere Dair Araştırma Örnekleri, A. Acaravcı, Ed. Ankara: Nobel
Akademik Yayıncılık Eğitim Danıșmanlık, 2018, pp. 367-369.

[9] Martinez-Gonzalez, M. A., Gual, P., Lahortiga, F., Alonso. Y., de Irala-Estevez, J., Cervera, S. (2003). Parental factors, mass media influences, and the onset of eating disorders in a prospective population-based cohort. Pediatrics, 111 (2), 31520.

[10] Swanson, S. A., Crow, S. J., Le Grange, D., Swendsen, J., Merikangas, K. R. (2011). Prevalence and correlates of eating disorders in adolescents. Arch Gen Psychiatry, 68, 714-723.

[11] Fichter, M. M., Quadflieg, N., Hedlund, S. (2006). Twelveyear course and outcome predictors of anorexia nervosa. Int J Eat Disord, 39 (2), 87-100.

[12] Saleh, R. N., Salameh, R. A., Yhya, H. H., Sweileh, W. M. (2018). Disordered eating attitudes in female students of AnNajah National University: a cross-sectional study. Journal of Eating Disorders, 6, 16.

[13] Xie, B., Liu, C., Chou, C. P., Xia, J., Spruijt-Metz, D., Gong, J., Li, Y., Wang, H., Johnson, C. A. (2003). Weight perception and psychological factors in Chinese adolescents. J Adolesc Health, 33, 202-210.

[14] Balhara, Y. P. S., Mathur, S., Kataria, D. K. (2012). Body Shape and Eating Attitudes among Female Nursing Students in India. East Asian Arch Psychiatry, 22, 70-4.

[15] Ozmen, D., Ozmen, E., Ergin, D., Cetinkaya, A. C., Sen, N., Dundar, P. E., Taskin, E. O. (2007). The association of selfesteem, depression and body satisfaction with obesity among Turkish adolescents. BMC Public Health, 16 (7), 80.

[16] Yamamoto, C., Uemoto, M., Shinfuku, N., Maeda, K. (2007). The usefulness of body image tests in the prevention of eating disorders. Kobe J Med Sci, 53, 79-91.

[17] Juarascio, A., S., Forman, E., M., Timko, C. A., Herbert, J. D., Butryn, M., Lowe, M. (2011). Implicit internalization of the thin ideal as a predictor of increases in weight, body dissatisfaction, and disordered eating. Eat Behav, 12 (3), 207-13.

[18] Keel, P. K., Forney, K. J. (2013). Psychosocial risk factors for eating disorders. Int J Eat Disord, 46 (5), 433-9.

[19] Stice, E., Ng, J., Shaw, H. (2010). Risk factors and prodromal eating pathology. J Child Psychol Psychiatry, 51 (4), 518-25.

[20] Evans, E. H., Tovée, M. J, Boothroyd, L. G., Drewett, R. F. (2013). Body dissatisfaction and disordered eating attitudes in 7- to 11-year-old girls: testing a sociocultural model. Body Image, $10(1), 8-15$.

[21] Figueiredo, R. A. O., Simola-Ström, S., Isomaa, R., Weiderpass, E. (2018). Body dissatisfaction and disordered eating symptoms in Finnish preadolescents. Eat Disord, 24, 1-18.

[22] Hrabosky, J. I., Cash, T. F., Veale, D., Neziroglu, F., Soll, E. A., Garner, D. M, Strachan-Kinser, M., Bakke. B., Clauss, L. J., Phillips, K, A. (2009). Multidimensional body image comparisons among patients with eating disorders, body dysmorphic disorder, and clinical controls: A multisite study. Body Image, 6 (3), 155-63.

[23] Shirasawa, T., Ochiai, H., Nanri, H., Nishimura, R., Ikeda, K., Hoshino, H., Kokaze, A. (2016). Association between distorted body image and changes in weight status among normal weight preadolescents in Japan: a population-based cohort study. Arch Public Health, 20 (74), 39. 
[24] Argyrides, M., Kkeli, N. (2015). Predictive factors of disordered eating and body image satisfaction in Cyprus. Int $\mathrm{J}$ Eat Disord, 48 (4), 431-5.

[25] Alkazemi, D., Zafar, T. A., Ebrahim, M., Kubow, S. (2018). Distorted weight perception correlates with disordered eating attitudes in Kuwaiti college women. Int J Eat Disord, 51 (5), 449-458.

[26] Nagata, J. M., Garbe. r A. K., Tabler. J. L., Murray, S. B., Bibbins-Domingo, K., (2018). Differential Risk Factors for Unhealthy Weight Control Behaviors by Sex and Weight Status Among U.S. Adolescents. J Adolesc Health, 63 (3), 335-341.

[27] Yiu, A, Murray, S. M., Arlt, J. M., Eneva, K, T., Chen, E. Y. (2017). The importance of body image concerns in overweight and normal weight individuals with binge eating disorder. Body Image, 22, 6-12.

[28] Stice, E., Shaw, H. E. (2002). Role of body dissatisfaction in the onset and maintenance of eating pathology: a synthesis of research findings. J Psychosom Res, 53 (5), 985-93.

[29] Fulkerson, J. A., Strauss, J., Neumark-Sztainer, D., Story, M., Boutelle, K. (2007). Correlates of psychosocial well-being among overweight adolescents: The role of the family. Journal of Consulting and Clinical Psychology, 75 (1), 181-186.

[30] Cromley, T. R., Neumark-Sztainer, D., Story, M., Boutelle, K. (2010). Parent and family associations with weight-related behaviors and cognitions among overweight adolescents. The Journal of Adolescent Health: Official Publication of the Society for Adolescent Medicine, 47 (3), 263-269.

[31] Rodríguez Martín, A., Novalbos Ruiz, J. P., Martínez Nieto, J. M., Escobar Jiménez, L., Castro De Haro, A. L. (2004). Epidemiological study of the influence of family and socioeconomic status in disorders of eating behaviour. Eur $\mathrm{J}$ Clin Nutr, 58, 846-852.

[32] Galloway, A. T., Fiorito, L., Lee, Y., Birch, L. L. (2005). Parental pressure, dietary patterns and weight status among girls who are 'picky eaters'. J Am Diet Assoc, 105, 451-548.

[33] Ciao, A. C., Accurso, E. C., Fitzsimmons-Craft, E. E., Lock, J., Le Grange, D. (2015). Family functioning in two treatments for adolescent anorexia nervosa. The International Journal of Eating Disorders, 48 (1), 81-90.
[34] Wallis, A., Rhodes, P., Dawson, L., Miskovic-Wheatley, J., Madden, S., Touyz, S. (2017). Relational containment: exploring the effect of family-based treatment for anorexia on familial relationships. Journal of Eating Disorders, 5, 27.

[35] Pinto, C., Ferreira, C., Mendes, A. L., Trindade, I. A. (2017). Social safeness and disordered eating: Exploring underlying mechanisms of body appreciation and inflexible eating. Eat Weight Disord, 22 (2), 303-309.

[36] Suisman, J. L., Burt, S. A., Mc Gue, M., Iacono, W. G., Klump, K. L. (2011). Parental divorce and disordered eating: An investigation of a gene-environment interaction. Int J Eat Disord, 44 (2), 169-77.

[37] O’Connor, S. M., Klump, K. L., VanHuysse, J. L., McGue, M., Iacono W. (2016). Does Parental Divorce Moderate the Heritability of Body Dissatisfaction? An Extension of Previous Gene-Environment Interaction Effects. The International journal of eating disorders, 49 (2), 188-192.

[38] Wallis, A., Miskovic-Wheatley, J., Madden, S., Alford, C., Rhodes, P., Touyz, S. (2018). Does continuing family-based treatment for adolescent anorexia nervosa improve outcomes in those not remitted after 20 sessions? Clin Child Psychol Psychiatry, 23 (4), 592-600.

[39] Le Grange, D., Hughes, E. K., Court, A., Yeo, M., Crosby, R. D., Sawyer, S. M. (2016). Randomized Clinical Trial of Parent-Focused Treatment and Family-Based Treatment for Adolescent Anorexia Nervosa. J Am Acad Child Adolesc Psychiatry, 55 (8), 683-92.

[40] Garner, D. M., Garfinkel, P. E. (1979). The Eating Attitudes Test: An Index Of The Symptoms Of Anorexia Nervosa. Psychological medicine, 9 (2), 273-279.

[41] Savaşır, I., Erol, N. (1989). Eating Attitude Test: Anorexia Nervosa Symptom Index. Psikoloji Dergisi, 7, 19-25.

[42] Henderson, M., Freeman, C. P. L. (1987). Bulimic Investigatory Test Edinburgh. A self-rating scale for bulimia the "BITE". British Journal of Psychiatry, 150, 18-24.

[43] Kıran, S. G., Agargun, M. Y., Kara, H. (2000). "Dissociative experiences and eating attitudes in university students". 36. National Psychiatry Congress, Antalya, Turkey. 